\title{
Prevención, "mano dura" y territorios peligrosos. El delito en Diario Popular y La Nación hacia 1983
}

\author{
Prevention, "firm hand" and dangerous territories. Crime in La \\ Prensa and La Nación in 1983
}

María Paula Gago mariapaulagago@gmail.com

http://orcid.org/0000-0001-8148-1499

Instituto de Investigaciones Gino Germani;

Facultad de Ciencias Sociales; Universidad de Buenos Aires/ Consejo Nacional de Investigaciones Científicas y Técnicas (Argentina)

\section{Resumen}

En este trabajo se retoman un conjunto de problemáticas abordadas en trabajos previos que remiten a los modos de narración del delito hacia fines de la última dictadura cívico militar ocurrida en Argentina (1976-1983). Su objetivo es acotado: se propone analizar el modo en que las narrativas policiales delimitaban a ciertos territorios como peligrosos y sostenemos que dichas modalidades enunciativas siguen vigentes, aunque con variaciones, en los relatos actuales para cartografiar la "inseguridad". Tomaremos como objeto de análisis un conjunto de unidades informativas que se publicaron en Diario Popular y La Nación entre junio y julio de 1983 sobre el gran Buenos Aires. La metodología utilizada es análisis crítico del discurso.

Palabras clave: noticia policial; control social; cartografía del delito; dictadura argentina; inseguridad. 


\begin{abstract}
In this work, a set of problems addressed in previous works are taken up, which refer to the ways of narrating crime towards the end of the last military civic dictatorship that took place in Argentina (1976-1983). Its objective is limited: it is proposed to analyze the way in which the police narratives delimit certain territories as dangerous and we maintain that these enunciative modalities are still valid, although with variations, in the current accounts to map the "insecurity". We will take as an object of analysis a set of informative units about gran Buenos Aires that were published in the newspapers Diario Popular and La Nación between june and july 1983. The methodology used is critical analysis of discourse.
\end{abstract}

Keywords: police news; social control; crime cartography; argentine dictatorship; insecurity.

En el presente trabajo proponemos analizar ciertas estrategias periodísticas para narrar el delito hacia 1983, en los días finales del gobierno dictatorial. La hipótesis que sostenemos es que si bien la representación gráfica del delito es una característica distintiva de los relatos mediáticos sobre la inseguridad, las modalidades enunciativas para delimitar "territorios peligrosos", demandar prevención en términos de vigilancia estricta y "mano dura" ya estaban presentes en los modos de narrar el delito hacia el período final de la última dictadura cívico militar.

En estudios previos (Gago, 2015; 2017) se ha puesto de manifiesto que el comportamiento de la prensa respecto de los métodos represivos y de control social durante el período 1976-1983 es cambiante puesto que en un primer momento (1976-1978) la clave interpretativa fue la de utilizar una retórica propia del género policial para referirse a la "lucha antisubversiva" y reducirla a una cuestión de seguridad, mientras que hacia el final del periodo se verifica un viraje en el encuadre: todos los acontecimientos delictivos, incluso aquellos que se pueden calificar como "delito común" adquirían connotaciones políticas.

En las sociedades de masas, los medios de comunicación son agentes privilegiados para consolidar y difundir los imaginarios sociales. Es decir, las representaciones globales de la vida social, de sus agentes, de sus instancias y autoridades; los mitos políticos, los modelos formadores de mentalidades y de comportamientos, los símbolos, entre otros aspectos (Baczko, 1999). Si bien los medios funcionan como "mediadores generalizados", también 
cumplen otros roles. Fundamentalmente, el de ser instrumentos del diálogo social, ya que toda sociedad debe tener un umbral de informaciones comunes para debatir las acciones colectivas. Pero también cumplen roles que, más allá de sus objetivos "puramente" periodísticos, se vinculan con su acción dentro de un sistema político. En este sentido, Borrat (1989) define a la prensa como un actor político con influencia propia en la comunidad. Entendiendo a todo actor político como todo actor colectivo o individual capaz de afectar al proceso de toma de decisiones en el sistema político.

Partimos de considerar a la noticia policial como una noticia política (Saítta, 1998) y un instrumento histórico y crítico (Ludmer, 1999) esto es, como un discurso articulador de identidades sobre las víctimas, los victimarios, que tematiza sobre el rol del Estado, la institución policial y la justicia, y que exige orden y control social.

Trabajaremos sobre unidades informativas publicadas entre junio y julio de 1983 en Diario Popular y La Nación. Los mismos fueron seleccionados por su circulación y ámbito de influencia y porque, en función del contrato de lectura de cada uno (Verón, 1985), nos permiten comparar las continuidades y variaciones en los discursos sobre el delito en la prensa seria y la prensa amarilla.

\section{Aspectos teórico metodológicos}

En lo que respecta a la elección de los materiales periodísticos, nos parece pertinente mencionar que hemos elegido a los diarios La Nación y Diario Popular, porque consideramos que los medios seleccionados cumplen con el rol de instaladores de opinión en la sociedad, en las instituciones y en los demás medios masivos de comunicación. Por otra parte, si bien como afirma Steimberg (1987) hacia los años ochenta la "frontera" entre prensa "seria" y "amarilla" era cada vez menos nítida, consideramos que hemos elegido diarios que le darán al estudio una mayor exhaustividad -entre otras cuestiones- porque nos permitirán identificar variaciones y/o continuidades en los modos de construcción de la noticia policial, tanto en medios que otorgaban centralidad al policial en relación a aquellos que le otorgaban primacía a las cuestiones políticas y económicas. Dentro de la prensa de referencia ubicamos a La Nación, mientras que a Diario Popular lo situamos dentro de la prensa amarilla.

En total trabajamos sobre seis artículos; tres publicados en Diario Popular y tres en La Nación, que se detallan en la parte final de este trabajo y que nos permitieron ilustrar las estrategias periodísticas para narrar el delito y delimitar los "territorios peligrosos". 
La metodología de análisis empleada se orienta a analizar los modos en que las prácticas sociales de producción y recepción de sentidos en un contexto determinado (Verón, 1988) afectan a la construcción de los discursos que circulan socialmente. En este caso, el análisis se centrará en dos diarios, desde el punto de vista de sus condiciones de producción.

Analizaremos los discursos periodísticos que componen el corpus de trabajo en sus tres dimensiones -temática, retórica y enunciativa- atendiendo a las marcas y huellas que dan cuenta de los componentes enunciativos: enunciador, destinatario y el "nexo" que se establece entre esos lugares (Verón, 1985: 182).

Asimismo, de acuerdo a lo dicho y rescatando el aporte de van Dijk (1997), abordamos a los textos informativos a partir de una serie de preguntas con el objetivo de analizarlos de forma crítica y que nos permitan identificar: quiénes son los actores de las noticias, cuáles son activos y cuáles pasivos, qué fuente se citan y cómo se legitiman.

Si bien estas preguntas se relacionan de modo directo con el proceso de elaboración de las noticias, no son "inherentes' al artículo informativo sino recurrentes universales de la narrativa o del discurso" (van Dijk, 1997: 61). Cada una de dichas preguntas, siguiendo a van Dijk, presupone la variación, elección y decisión en muchos niveles del análisis textual y, a su vez, cada elección presupone creencias, opiniones, actitudes e ideologías.

A su vez, para el estudio de los discursos periodísticos y su construcción tendremos en cuenta conceptos fundamentales de la teoría de la noticia: consideración de las rutinas periodísticas, jerarquización y estructuración de agendas temáticas y atributivas, la concepción de noticiabilidad que sostiene cada órgano mediático y el manejo de criterios que posibilitan el pasaje del acontecimiento, ruptura en la cotidianidad, a la noticia, las modalidades discursivas o de enunciación específicas -vinculadas al contrato de lectura (Verón, 1985)- y las atenientes al diseño de las unidades informativas y la relación con las fuentes (Wolf, 1991; McCombs y Shaw, 1993; Mar de Fontcuberta, 1993 cit. por Ruiz y Albertini, 2008).

También rescatamos los aportes teóricos del género periodístico policial (Caimari, 2004 y 2012; Saítta, 1998) que permitirán identificar sus características distintivas, de acuerdo al momento histórico, como así también su inclusión en series culturales más amplias, que permitan analizar los artículos en tanto "relatos del orden" en un contexto dictatorial.

\section{Los medios y su relación con la dictadura}


La implantación del llamado Proceso de Reorganización Nacional en la Argentina el 24 de marzo de 1976 tuvo el propósito proclamado de aniquilar a la guerrilla sin las trabas que suponía la presencia de un sistema constitucional, por complaciente que este fuera con la autoridad militar.

En consecuencia, estimulada por los golpes de la guerrilla urbana (aunque sus objetivos eran más ambiciosos) la Junta Militar asumió, junto con el apoyo de la coalición civil, el rol de refundar la sociedad en los planos político, económico, cultural, entre otros (Canitrot, 1980; Cavarozzi, 2006; Novaro y Palermo, 2003; Canelo, 2009 y 2016).

Uno de los instrumentos principales del proyecto refundacional fue el plan sistemático de secuestros masivos de opositores políticos en centros clandestinos de detención, posterior tortura, asesinato y desaparición, en una vasta represión ilegal que produjo miles de desaparecidos.

La planificación general y la supervisión táctica estuvo en manos de las cúpulas castrenses, que habían tomado el poder estatal, pasando por la cadena de mandos, hasta los grupos de tareas que ejecutaban directamente las acciones criminales, poniendo de relieve el carácter institucional de la acción y el comportamiento colectivo.

El terrorismo de Estado estuvo dirigido contra obreros, dirigentes políticos y sindicales opositores, miembros de las organizaciones político-armadas y militantes políticos de diversa índole (periodistas, estudiantes, trabajadores sociales, sacerdotes y sectores movilizados políticamente). También las operaciones clandestinas represivas fueron utilizadas como un recurso criminal para saldar disputas de poder inter e intra Fuerzas Armadas y alcanzó, aunque más excepcionalmente, a empresarios, parientes o amigos de las víctimas originales, entre otros. Además de las organizaciones guerrilleras, el ámbito sindical y el educativo fueron prioritarios para la represión militar. La práctica represiva clandestina no sólo tuvo como objetivo silenciar definitivamente a los opositores, sino también lograr un certero disciplinamiento social, profundizar la despolitización de la sociedad civil y desgarrar los lazos de solidaridad social que habían crecido en los años anteriores.

El final de la dictadura cívico militar y el paso a la apertura democrática se produjo por colapso.

El fracaso en materia económica, el desprestigio internacional del que gozaban las Fuerzas Armadas como consecuencia de su accionar represivo, la derrota en Malvinas y las propias fracturas internas que estuvieron presentes desde los prolegómenos del golpe de Estado de 1976, desembocaron en una realidad diferente, determinada por una agenda en la que la instauración de la democracia aparecía como un objetivo a alcanzar en el menor tiempo posible. Los planes de los militares fueron reemplazados por una demanda generalizada de 
cambios que hizo imposible que el gobierno pudiera ser un conductor razonable del proceso de transición.

Sobre la relación entre los medios y el gobierno dictatorial debemos señalar que la Junta Militar que asumió en 1976 estableció su propio marco legal. Y el mismo 24 de marzo publicó el Comunicado Nro. 19 en el que establecían:

será reprimido con reclusión de hasta 10 años el que por cualquier medio difundiere, divulgara o propagara noticias, comunicados o imágenes, con el propósito de perturbar, perjudicar o desprestigiar la actividad de las fuerzas armadas, de seguridad o policiales.

Según indican Postolski y Marino (2006) en la misma madrugada del golpe fueron convocados los directivos de los medios de comunicación metropolitanos a la sede del Comando General del Ejército. Allí, según señalan los autores, se les informó la decisión de implantar un régimen de censura y les fue entregada una cartilla con el fin de facilitar la tarea del censor. Además se creó un Servicio gratuito de lectura previa, que "de la dureza del primer momento se pasó a distintas instancias de negociación" (Postolski y Marino, 2006: 6). De este modo, el Servicio gratuito de lectura previa dejó de funcionar al mes, y en los canales de televisión surgieron tácticas para "sortear" las prerrogativas de los "asesores literarios", quienes se irán ablandando con los años.

En cuanto a los medios gráficos, Borrelli (2016) y Díaz (2002) indican que Videla convocó a los directivos de los más destacados diarios capitalinos a una reunión el 1 de abril de 1976; encuentros que en adelante se llevarían a cabo con grupos reducidos de dos o tres periodistas (Díaz, 2002). En esa oportunidad, los directores de la prensa nacional y de las radios privadas que se reunieron con las más altas autoridades del gobierno militar, concertaron pautas de autocensura con la justificación de no "favorecer" a las organizaciones guerrilleras (Borrelli, 2016).

Entre otras medidas se allanaron empresas periodísticas, se detuvieron, encarcelaron y desaparecieron periodistas. El control de los servicios de radiodifusión había pasado a manos del Estado hacia 1973, a partir de pautas legales que habían sido modificadas durante el mandato del general Lanusse, que estableció que las licencias concedidas a los canales privados se contarían desde el día en que habían sido entregadas y no desde la fecha en que se habían iniciado las transmisiones. Así, la estructura de propiedad de los medios pasó a ser fundamentalmente estatal.

Cuando la dictadura militar llegó al poder se encontró con el monopolio de la televisión, que le permitió ejercer la censura de la información que recibía (Muraro, 1987: 22-23). De este modo 
las emisoras de TV fueron manejadas por los interventores militares: Canal 13 pasó a manos de la Armada, Canal 11 a la Fuerza Aérea y Canal 9 fue adjudicado al Ejército, y en 1984 pese a que el resto de los medios se mantuvo en manos del Estado hasta la década del noventa- fue devuelto a su antiguo dueño -el empresario teatral Alejandro Romay - tras un fallo de la justicia. Canal 7, Argentina Televisora Color (ATC) tuvo una dirección tripartita (Mestman, 1992; Muraro, 1987; Postolski y Marino, 2006).

La dictadura fue clara en su accionar frente a las empresas de prensa: los medios críticos fueron intervenidos o clausurados; "aquellos que quisieron mantener algún rasgo de autonomía frente a su accionar político eran reprimidos, y aquellos que funcionaron como adictos, fueron tratados con esmero. Se priorizó la relación con las empresas de prensa, y se contempló situaciones de privilegio para el sector" (Postolski y Marino, 2006: 8).

\section{La Nación (1870)}

El diario La Nación fue fundado en 1870 por Bartolomé Mitre, político, militar, quien se desempeñó como presidente, e impulsó la organización nacional. Desde su comienzo el matutino luchó por ocupar posiciones dominantes en el campo periodístico y se consolidó como un actor relevante que analizaba y explicaba las cuestiones políticas, económicas y sociales del país.

El matutino definía como interlocutores privilegiados al Estado, los gobiernos, los sectores que "se encontraban en las posiciones más altas de las estructuras del poder político, del sistema económico y de la jerarquía del poder social" (Sidicaro, 1993: 10).

A lo largo del tiempo, el diario conservó su tradición liberal-conservadora y la valoración positiva de las instituciones democráticas, siendo esto último un postulado contradictorio ya que aceptaba las interrupciones militares en tanto "pusieran fin al poder de los sectores que el propio diario calificaba como 'no democráticos"' (González, 2009).

En 1976, La Nación adhirió a la iniciativa militar que derrocó al gobierno de María Estela Martínez de Perón, puesto que -al igual que un amplio conjunto de sectores sociales y políticos- vieron esa alternativa como necesaria para recuperar el normal funcionamiento de la vida institucional: "la naturaleza de la situación a la que se ponía fin y la definición liberalconservadora de los nuevos ocupantes del poder constituyeron, sin duda, factores decisivos para la adopción de esa orientación" (Sidicaro, 1993: 442-445). Su apoyo vio su recompensa cuando -después de la muerte del empresario Graiver- el matutino, junto con otros diarios, fue 
objeto de una negociación para hacerse cargo de las acciones que el empresario tenía en Papel Prensa.

Cuando el autodenominado Proceso de Reorganización Nacional mostró signos de agotamiento irreversible, el matutino realizó críticas en sintonía con el clima social aunque explicitó que la lucha contra la "subversión" no debía revisarse (Blaustein y Zubieta, 1999), postura que mantuvo y que volvió a expresar 24 años después en un editorial titulado "Los indultos" del 30 de diciembre de 1990 y en otro publicado el 23 de noviembre de 2015 cuyo título reza "No más venganza".

\section{Diario Popular (1974)}

El 1 de julio de 1974 fue la primera edición de Diario Popular cuya historia está marcada por la fatalidad. La tragedia que rodeó los comienzos del diario se refiere al secuestro de David Kraiselburd, su fundador, quien "había sido raptado por la organización político-militar Montoneros el 25 de junio y asesinado el 17 de julio. Su hijo, Raúl, quedó a cargo del emprendimiento" (Borelli, 2013: 44).

Diario Popular venía a ocupar el "vacío" dejado por Crónica, el diario de Héctor Ricardo García, que había sido clausurado durante el gobierno de Isabel Perón.

La cobertura de casos policiales fue el eje del diario. Con informaciones breves y una diagramación más prolija que otros diarios como, por ejemplo, La Nación que no diferenciaba secciones, logró un lugar en el mercado y sobrevivió a la reaparición del diario de García (Seis periodistas, 2007).

En cuanto al contrato de lectura, Diario Popular establece una posición editorial cómplice con el lector que apela a un lenguaje coloquial, a la hipérbole y el sensacionalismo como retórica dominante, privilegiando la cobertura de casos policiales al igual que los deportivos, pero dándole lugar también a las noticias nacionales por sobre las internacionales.

El director del diario, Raúl Kraiselburd, durante los años de la dictadura mantuvo una estrecha relación con el gobierno militar. En la reunión de la SIP de 1981, Claudio Escribano y Raúl Kraiselburd defendieron la existencia de la libertad de prensa en la Argentina. Ese mismo año, de acuerdo a una nota de Horacio Verbitsky, Raúl Kraiselburd colaboró con el general Ramón Camps (Jefe de la Policía bonaerense) en la edición de un libro con el cual el represor pretendía desmentir las denuncias de torturas hechas por otro periodista, Jacobo Timerman. Hacia 1977 el director del Diario Popular se vio involucrado de manera directa por un caso policial de resonancia: el asesinato de David Kraiselburd, su hijo. 


\section{Resultados}

Tal como sostiene Ludmer el delito es una categoría cambiante (por eso histórica), flexible, que delimita y marca fronteras en el interior de una cultura, a la vez que articula una noción de victimario, víctima, Estado, de política, etcétera. Desde este punto de vista, consideramos que la noticia policial no es un segmento "inocente" de la zona blanda de los diarios puesto que es un espacio desde el cual se instauran representaciones sobre la propia identidad y los otros y se reclaman acciones por parte del Estado.

La crónica policial es el espacio para la narración de asesinatos, robos, hurtos. En este sentido, se trata de relatos que informan sobre los acontecimientos protagonizados por aquellos que se ubican al margen de la ley. Sin embargo, durante la dictadura se utilizó una retórica del género policial para darle visibilidad a la "lucha antisubversiva" y de este modo naturalizar como "enfrentamiento" entre fuerzas de seguridad y "elementos sediciosos", lo que luego se supo fue el terrorismo de Estado. Estas formas de informar sobre la represión ilegal a partir de la utilización de una retórica propia del género policial se expresan en titulares como:

“10 extremistas abatidos", 12 de noviembre de 1976, Diario Popular.

"Ocho detenidos por subversión en la Universidad del Sur", 13 de noviembre de 1976, La Nación.

De todos modos, el período comprendido entre 1976-1983 es inestable en cuanto al modo de tematizar y abordar los hechos delictivos (Gago, 2017).

En consecuencia, identificamos un primer comprendido entre 1976-1978 en el cual el modelo delictivo predominante es el de la delincuencia subversiva. Un segundo momento de auge de los asesinatos espectaculares y un tercer momento de retorno del terror (Gago, 2015 y 2017). Dentro de cada uno de estos momentos se visualizan la predominancia de ciertos modelos delincuenciales: en el primero, la subversión; en el segundo, los asesinos como los hermanos Schoklender; en el tercero, la información sobre los asesinatos del publicista Marcelo Dupont (1982) y de los militantes Cambiasso y Pereyra Rossi (1983) fueron inscriptas en una serie que "reactualizaba la cuestión subversiva", casi ausente de los sumarios periodísticos desde fines de 1978, pero desde un marco interpretativo que -en un movimiento pendular- "abandonaba" la retórica delictiva de la que otrora se había valido la prensa para informar sobre el "delito 
subversivo" y "la lucha antisubversiva" -y que nutriría a la posterior "teoría de los dos demonios"- y se desplazaba hacia un discurso de tipo informativo que interpretaba en clave política inclusive unidades informativas de la agenda policial.

En virtud de estos modelos delincuenciales se configuraron dos narrativas (Gago, 2015 y 2017): una de corte represiva autoritaria, extensible no sólo a la militancia/oposición política sino también a modelos de delincuentes que si bien eran considerados de "alta peligrosidad" (parricidas, infanticidas y asesinos) no respondían al estereotipo del "subversivo" construido primero en el discurso militar (Casabona, 2013) y luego retomado por los medios de prensa. La segunda, de índole correctiva, pero no por eso menos punitiva y estigmatizadora, veía al "delincuente común" como un "inadaptado social recuperable" que, ante la carencia de "contención familiar" y la falta de recursos económicos y educativos, delinquía para sobrevivir. Hacia finales del periodo dictatorial, la crónica policial se convirtió en espacio para delimitar geografías peligrosas y se acuñaron estilos discursivos sostenidos en la reiteración de metáforas como "ola" de robos, "escalada" de violencia, a la par que se asentaba la utilización de una narrativa represiva que demandaba "mano dura", pero ya no para exterminar la delincuencia subversiva.

\section{Territorios del miedo}

Si bien la identificación de territorios peligrosos está presente a principios del siglo XX en el discurso periodístico (Saítta, 1998) los periodistas no abordaban el mundo de los bajos fondos con extrañamiento sino con una proximidad que les permitía "legitimarse sobre la base del íntimo conocimiento que tenían de él" (Pereyra, 2009: 41). Sin embargo, esa manera nostálgica y hasta condescendiente de retratar la periferia peligrosa desaparece.

Durante 1983 las "noticias" sobre el gran Buenos Aires ocuparon un espacio central en la superficie redaccional de los diarios, no sólo para informar sobre olas delictivas sino también sobre la construcción de aceras, entrega de premios, construcción de hospitales ("Otros cuatros hospitales harán en el conurbano", 6/6/1981).

Presumiblemente, el gran Buenos Aires ganaba espacio en la superficie redaccional puesto que constituía una zona de peso e importancia en la realidad del país, debido a la cantidad de población y a su incidencia en los resultados electorales de octubre de 1983. 
Respecto del delito común, Diario Popular inscribe en la serie informativa "territorios del miedo" de la agenda policial a las "olas de saqueos contra fábricas, negocios y viviendas" ("Lanús Oeste, ahora capital del delito”, 28/6/1983).

Según informaba el diario, una ola de asaltos que incluía el saqueo de varias fábricas con la presencia de "hasta mujeres pistoleras", mantenía en vilo a una amplia zona del partido de Valentín Alsina, Lanús oeste, en donde:

hoy impera el miedo y son pocos los que se animan a salir en horas de la noche (...) Durante sus raid, los malvivientes también se dedican al asalto de domicilios particulares, así como someten a ultrajes a indefensas mujeres ("Lanús Oeste, ahora capital del delito", 28/6/1983).

En algunos casos, no sólo se robaban bienes materiales sino que, según narraba Diario Popular, tal como había ocurrido en un instituto de belleza femenino de Lanús, "dos malhechores jóvenes irrumpieron a cara descubierta, armados con sendos revólveres, y tras obtener el dinero y alhajas de los presentes, violaron a dos mujeres" ("Más asaltos", 25/6/1983). Testigos de estos hechos fueron entrevistadas por Diario Popular y manifestaron su indignación por la pasividad policial ya que pese a que se denunció a pocos minutos de haber ocurrido, un patrullero se hizo presente casi dos horas después. "De esa forma -dijo una vecina del local- los ladrones y depravados actúan con total impunidad" ("Lanús Oeste, ahora capital del delito", 28/6/1983). Como lo exige la crónica policial había que estereotipar a los delincuentes: eran jóvenes que vestían jeans azules y camperas inflables.

No muy lejos de allí, en jurisdicción de Valentín Alsina, los ladrones habían visitado varias industrias, entre ellas una fábrica de calzado, una curtiembre y un depósito de comestibles. Diario Popular remarcaba que si bien la seccional de policía estaba a cien metros de la fábrica de calzados, "los ladrones se llevaron un enorme bulto sin problemas" (Ídem).

Las noticias sobre el gran Buenos Aires y sus problemas no eran exclusivas de Diario Popular. Por su parte, La Nación desde 1981 había incluido en su superficie redaccional la publicación de artículos destacados respecto del resto y antecedidos por una volanta que rezaba "El mundo del Gran Buenos Aires". La información que se incluía en esta suerte de espacio especial dedicado al gran Buenos Aires no necesariamente era negativa. Por ejemplo, en la edición del 6 de junio de 1981, el diario publicaba una noticia sobre cuatro hospitales que se construirían en el conurbano. 
La ola de delitos que "aquejaba" a la zona motivó un editorial de La Nación en el cual argüía que:

\begin{abstract}
...pocos meses atrás, en el Gran Buenos Aires, y con mayor asiduidad en el sector Sur, viajar en colectivo de noche era un riesgo grande. Los asaltos contra pasajeros y conductores se sucedían a diario, a tal punto que algunas líneas interrumpieron sus servicios. Los resultados de estos delitos variaron desde el despojo de dinero y otros efectos hasta el asesinato las violaciones y toda clase de desmanes. Además del caso de los colectivos, los atracos en comercios y a transeúntes, más los delitos privados consumados contra mujeres, contribuyeron a sembrar una suerte de terror entre los pobladores bonaerenses, aún en quienes viven próximos a las avenidas importantes ("Recrudecimiento del delito", 22/7/1983).
\end{abstract}

Después de un lapso de "aparente disminución del mal" ("Recrudecimiento del delito", $22 / 7 / 1983$ ), ese mismo sector provincial había vuelto a mostrarse como un campo dominado por varias gavillas con asaltos a colectivos, a negocios y a viviendas particulares, que tuvieron trágicos saldos y sobre los cuales, como ya mencionamos, Diario Popular también hacía referencia.

Abundaban los secuestros de parejas jóvenes, "hechos que derivan casi siempre en el asesinato del hombre y en el sometimiento de la mujer". Esas "verdaderas oleadas de graves delitos" (Ídem), habilitaban formas de reclamo por parte de La Nación, que incluían a las fuerzas del orden.

En primer lugar, cuando la policía informaba en términos estadísticos, se refería a una verdad que "podría calificarse de relativa, ya que toma en cuenta los delitos denunciados y aun los investigados de oficio en los casos en que se carece de una denuncia formal ante un hecho significativo" (Ídem).

Pero existía para el diario otra realidad de carácter absoluto, que es la que vivía y palpaba la población ante la incesante sucesión de delitos, que incluían los denunciados, los muchos no denunciados y aquellos que se encontraban, "lamentablemente, en una especie de término medio: las denuncias que la policía se niega a tomar por distintas razones" (Ídem). A su vez, el diario instaba a la policía de la provincia de Buenos Aires a cubrir la prevención del delito en el Estado más habitado del país y en la región de máxima concentración de la población. No contaba el número suficiente de hombres para una acción más intensa pero debía admitirse para La Nación, en cambio, que tenía los medios técnicos adecuados. Por eso, consideraba necesario una redistribución de fuerzas para actuar donde el delito era más frecuente: 
...porque el servicio de vigilancia no puede considerarse igual que uno de transporte público, que es reforzado en las horas consideradas pico y disminuido a medida que avanzan la noche y la madrugada, precisamente porque los delincuentes a los que nos referimos actúan al caer las sombras. La presencia policial en patrulleros perfectamente identificables además de los servicios que puedan cumplirse con los vehículos no identificables como de la policía, es imprescindible a toda hora en la calle y en constante circulación, por cuanto es el factor psicológico que da la sensación de una vía pública bajo control. Prueba de ello fueron las épocas en que la represión de la subversión determinó un gran énfasis en el aspecto preventivo, lo que derivó, indirectamente, en una singular disminución de la delincuencia común por temor a sus exponentes a ser confundidos con terroristas ("Recrudecimiento del delito", 22/7/1983).

En este ejemplo se puede advertir la apelación a una narrativa de corte autoritario represivo que, al interior del discurso, plantea un desplazamiento metonímico por medio del cual la prevención se equiparaba a vigilancia estricta, visualizable a partir de la figura del patrullero y formas de control social absoluto, basado en el temor que podía generar al delincuente ser confundido con un terrorista.

Es importante señalar, siguiendo la propuesta de van Dijk (1997), que si bien la policía es un actor principal y activo en la resolución de los crímenes, como así también una fuente sobrerrepresentada en las noticias sobre "crímenes", en esta serie en particular es interesante destacar la configuración de una narrativa contradictoria, presente en los relatos actuales de la "inseguridad", que por un lado reclama mayor presencia policial en las calles y "mano dura", a la vez que descree del correcto accionar de las fuerzas. Esto se verifica tanto en las citas previas que hemos hecho del diario La Nación como en Diario Popular. "la seccional de policía está a 100 metros del lugar, pero los ladrones se llevaron un enorme bulto sin problemas" (“Lanús Oeste, ahora capital del delito", 28/6/1983).

Por otro lado, la fuente policial, que es la que por excelencia legitima y otorga autoridad a la noticia sobre el crimen, es desplazada por el testimonio de los vecinos, empleados o dueños de los locales asaltados. De este modo, los testimonios de los testigos de estos hechos eran incluidos en la crónica policial de Diario Popular para poner de manifiesto la indignación que generaba la pasividad policial ya que, pese a que se denunciaban los hechos a pocos minutos de haber ocurrido, el patrullero se hacía presente casi dos horas después. "De esa forma - dijo una vecina del local- los ladrones y depravados actúan con total impunidad" ("Lanús Oeste, ahora capital del delito", 28/6/1983). 
Esta desconfianza y el recelo que había tenido la policía para dar datos sobre las tasas de delito son explicitados por La Nación:

...los informes policiales del año último -originados por el requerimiento periodísticoseñalaron que el incremento de la delincuencia no excedía de un diez a un quince por ciento, guarismos estos que las autoridades consideraron normales de acuerdo con (...) el constante aumento de la población de la zona o cinturón que rodea a la metrópoli (“Recrudecimiento del delito", 22/7/1983).

Van Dijk (1997) señala que la ideología se proyecta en los discursos de una forma polarizada: nosotros/otros. Todo discurso ideológico construye un nosotros ("los buenos", los que pertenecemos a un determinado grupo ideológico) y nos diferenciamos de otros (generalmente "Ios malos"). En esta serie informativa se diferencian a los "hombres y mujeres" (La Nación) y "vecinos" (12) (en términos de Diario Popular) ambos conjuntos semánticos tomados como sinónimos de "ciudadano" que:

\begin{abstract}
...regresan de noche a sus hogares después de trabajar, estudiar o desempeñar cualquier otra tarea en beneficio de la comunidad debe considerarse y protegerse con premura antes que la actual ola de delitos se imponga hasta mermar aun más en el ciudadano la voluntad de cumplir con las obligaciones o dedicaciones antes apuntadas a cambio de su seguridad personal ("Recrudecimiento del delito", 22/7/1983).
\end{abstract}

\title{
Conclusiones
}

La noticia policial es un tipo de relato que, como hemos señalado a lo largo del trabajo, habla sobre el delito, categoría histórica y por eso cambiante (Ludmer, 1999), y traza una frontera móvil que no sólo delimita y separa la cultura de la no cultura, sino que articula diferentes zonas, como el Estado, la política, los sujetos, la literatura. De aquí que el relato policial se inscriba en el campo de la comunicación política (Martini, 2009).

Lo dicho hasta aquí no reviste carácter novedoso puesto que desde sus orígenes el relato policial señala al delincuente como el sujeto que no se "ajusta" a las reglas establecidas y por lo tanto se ubica al margen de la ley.

Sin embargo, esto no desmerece la importancia de estudiar los núcleos argumentativos desarrollados por la prensa gráfica de circulación nacional, porque el contexto que de por sí 
resignifica y recontextualiza quién es el enemigo, cuál es el rol del Estado, qué es lo correcto, qué lo incorrecto, en suma: redefine los límites de lo pensable y de lo decible (Angenot, 2010). En lo relativo a los contratos de lectura propuestos por cada diario, debemos remarcar que en lo referente a la agenda de la "lucha antisubversiva" Diario Popular y La Nación son similares en su clasificación, aunque emplean modos de cobertura propios, dependientes del contrato de lectura y, en menor medida, de la agenda atributiva. Esto se advierte en rasgos estilísticos utilizados por cada diario. Por ejemplo: mientras La Nación presentaba las noticias vinculadas a "la lucha contra la subversión" bajo títulos como "Abatieron" o "murieron sediciosos en un enfrentamiento con las fuerzas de seguridad ", medios como Crónica o Diario Popular, que reproducían textualmente en el cuerpo de la nota el mismo comunicado oficial que sus competidores, titulaban utilizando la hipérbole narrativa, recurso de exageración propio del policial pero también del estilo sensacionalista que caracteriza a la prensa amarilla. Por ejemplo, "Detienen a seis extremistas y hallan un poderoso arsenal" (Diario Popular, 10/11/1976).

En lo que atañe a los modos de narrar la noticia policial, si bien La Nación utilizaba preferentemente un discurso de tipo informativo/argumentativo, evidencia a lo largo del período, sobre todo en la cobertura de casos escabrosos como el de Yiya Murano (Gago, 2017), un ligero desplazamiento en su contrato de lectura y en su agenda temática al jerarquizar la información policial en su oferta informativa y contar en clave narrativa el acontecimiento. En lo que respecta a Diario Popular, y en virtud de su contrato de lectura, la noticia policial ocupaba un lugar central de su agenda informativa.

Por otra parte, debemos señalar que se advierte -hacia fines del período dictatorial- la definitiva instalación de una narrativa mediática de corte represivo y autoritario para narrar el delito que delimitaba "territorios peligrosos" e igualaba prevención con vigilancia estricta y "mano dura".

En primer lugar, los medios le otorgaron centralidad en su agenda al gran Buenos Aires. Presumiblemente este territorio adquiere visibilidad puesto que, al tener una densidad poblacional considerable, importaba en tanto distrito electoral con peso e incidencia en las elecciones que se realizarían en octubre de 1983.

A su vez, la relevancia y el protagonismo de esta "zona" se asociaba a la "terrible sucesión de episodios delictivos" que hacían del primer cordón del conurbano un "territorio temible" ("Recrudecimiento del delito", 22/7/1983). Los hechos delictivos a los que tanto La Nación como Diario Popular hacían referencia eran unidades informativas que no recibían un tratamiento ininterrumpido, aunque sí contribuían a una serie ("asalto a parejas", "asalto y abuso a mujeres") y que se volvían una suerte de "muestra" que confirmaba la realidad del 
conurbano. Estos pedazos o fragmentos de realidad permitían confirmar la reiteración: "Ola de robos y violencia en el Gran Buenos Aires".

La demarcación de Lanús oeste como un "territorio inhabitable y peligroso" debido a la ola de asaltos -en un primer momento a fábricas y luego a comercios y particulares- se advierte primero en la oferta informativa de Diario Popular y repercutió rápidamente en la agenda de los otros medios informativos: concretamente La Nación, que no escatimó en pedir, no sólo en Lanús oeste sino también en otras jurisdicciones, aumento de la vigilancia policial identificable en las calles, para enfrentar el incremento de la delincuencia.

Como puede apreciarse hacia el final del periodo ya estaba "anclado" en los relatos mediáticos sobre el "delito común", la narrativa represiva autoritaria que otrora reclamaba vigilancia, extermino y "mano dura" para acabar con el peligro subversivo.

\section{Bibliografía}

Angenot, M. (2010). Los discursos sociales. Los límites históricos de lo pensable y lo decible. Buenos Aires: Siglo XXI.

Blaustein, E. y Zubieta, M. (1999). Decíamos Ayer. La prensa argentina bajo el proceso. Buenos Aires: Colihue.

Borrat, H. (1989). El periódico, actor político. Barcelona: Gustavo Gili.

Borrelli, M. (2011). Una 'batalla ganada': Clarín y la compra de Papel Prensa (1976-1978). En Saborido, J. y Borrelli, M. (Comp.). Voces y silencios: la prensa argentina y la dictadura militar (1976-1983) (pp. 19-53). Buenos Aires: Eudeba.

Borelli, J. (2012). Diario Popular. El matutino que rompió el mito de la crisis de la prensa escrita en Argentina. (Tesina de grado). Ciencias de la Comunicación, Facultad de Ciencias Sociales, Universidad de Buenos Aires.

Borrelli, M. (2016). Por una dictadura desarrollista. Clarín frente a los años de Videla y Martínez de Hoz (1976-1981). Buenos Aires: Biblos.

Brunetti, P. M. (2011). Crónica roja y sensacionalismo: maneras de hacer, maneras de Ver.
Revista
Oficios
Terrestres,
$1(26)$,
1-17.
Recuperado

de http://perio.unlp.edu.ar/ojs/index.php/oficiosterrestres/article/view/657.

Caimari, L. (Comp). (2007). La ley de los profanos. Delito, justicia y cultura en Buenos Aires (1870-1940). Buenos Aires: Fondo de Cultura Económica. 
Caimari, L. (2012). Mientras la ciudad duerme. Pistoleros, policías y periodistas en Buenos Aires, 1920-1945. Buenos Aires: Siglo XXI Editores.

Canelo, P. (2009). El proceso en su laberinto. La interna militar de Videla a Bignone. Buenos Aires: Prometeo.

Canelo, P. (2016). La política secreta de la última dictadura argentina (1976-1983). Buenos Aires: Edhasa.

Canitrot, A. (1980). La disciplina como objetivo de la política económica. Un ensayo sobre el programa económico del gobierno argentino desde 1976. Desarrollo Económico, 19(76), 453-475. doi: https://doi.org/10.2307/3466561.

Casabona, G. L. (2013). Clarín y La Nación en la construcción de representaciones sobre el 'enemigo interno' en tiempos de autoritarismo, violencia y represión (1969). Trabajo presentado en VII Jornadas de Jóvenes Investigadores, Instituto de Investigaciones Gino Germani, Buenos Aires.

Cavarozzi, M. (2006). Autoritarismo y democracia (1955-2006). Buenos Aires: Ariel.

Díaz, C. L. y Passaro, M. M. (2009). Papel prensa y la dictadura. Una historia de silencios, alianzas y oposiciones. En Verano, A. (Ed.). Medios de comunicación en la Argentina: diagnóstico y prospectiva (pp. 139-163), La Plata: Facultad de Periodismo y Comunicación Social, Universidad Nacional de La Plata.

Gago, M. P. (2015). Una historia de subversivos, asesinos y ladrones de gallinas. La noticia policial en la prensa gráfica de circulación nacional durante la última dictadura cívico militar en Argentina (1976-1983). (Tesis de Doctorado en Ciencias Sociales). Facultad de Ciencias Sociales, Universidad de Buenos Aires.

Gago, M. P. (2017). Modelos delincuenciales y narrativas mediáticas sobre el delito. Los diarios argentinos Clarín y Crónica durante el período 1976-1979. Austral Comunicación, 6(2), 305-342.

Recuperado

de

http://www.austral.edu.ar/ojs/index.php/australcomunicacion/article/view/203/236

"Lanús Oeste, ahora capital del delito", 28 de junio de 1983. Diario Popular: 10-1.

Llonto, P. (2003). La noble Ernestina. El misterio de la mujer más rica del país. Buenos Aires: Astralib.

Ludmer, J. (1999). El cuerpo del delito. Un manual. Buenos Aires: Perfil.

Martini, S. y Pereyra, M. (Ed). (2009). La irrupción del delito en la vida cotidiana. Buenos Aires: Biblos.

“Más asaltos", 25 de junio de 1983. Diario Popular: 10. 
Mestman, M. (1992). Estado y sistema de medios en Argentina 1966-1976. Buenos Aires: Carrera de Ciencias de la Comunicación, Facultad de Ciencias Sociales, Universidad de Buenos Aires (mimeo).

Muraro, H. (1987). La comunicación masiva durante la dictadura militar y la transición democrática en la Argentina 1973-1986. En Landi, O. (Comp). Medios, transformación cultural y política (pp. 15-45). Buenos Aires: Legasa.

Novaro, M. y Palermo, V. (2003). La Dictadura Militar 1976/1983. Buenos Aires: Paidós.

"Otros cuatros hospitales harán en el conurbano", 6 de junio de 1981. La Nación: 10.

Postolski, G. y Marino, S. (2006). Relaciones peligrosas: los medios y la dictadura entre el control, la censura y los negocios. Revista de Economía Política de las Tecnologías de la Información y Comunicación, 8(21). Recuperado de http://seer.ufs.br/index.php/eptic/article/viewFile/299/286.

"Recrudecimiento del delito", 22 de julio de 1983. La Nación: 8.

Saborido, J. y Borrelli, M. (Coord.) (2011). Voces y Silencios: prensa y política durante la dictadura militar (1976-1983). Buenos Aires: Eudeba.

Saítta, S. (1998). Regueros de tinta. El diario Crítica en la década de 1920. Buenos Aires: Sudamericana.

Seis Periodistas (2007). Diario Popular, otro estilo para lo cotidiano. Recuperado de http://seisperiodistas.blogspot.com.ar/2007/10/diario-popular.html

Steimberg, O. (1987). Prensa amarilla/prensa blanca: notas sobre una conocida y no definida oposición de géneros. En Rivera, J. y Romano, E. Claves del periodismo argentino actual (pp. 149-159). Buenos Aires: Tarso.

Van Dijk, T. A. (1997). Racismo y análisis crítico de los medios. Barcelona: Paidós.

Verón, E. (1985). El análisis del 'Contrato de Lectura', un nuevo método para los estudios de posicionamiento de los soportes de los media. Les Medias: experiences, recherches actuelles, aplications. París: Institut de Recherches et d'Etudes Publicitaires. 